\title{
Ritmos de resistencia en la ficción de Anacristina Rossi ${ }^{1}$
}

\section{Linda J. Craft ${ }^{2}$}

\author{
North Park University, Chicago, Estados Unidos
}

\begin{abstract}
resumen
Se analizan las relaciones de sentido, incluidos los componentes simbólicos, entre algunas de las manifestaciones de la música afroamericana y afrocaribeñas (el blues y el reggae) y dos novelas de la escritora costarricense Anacristina Rossi. Se describe el papel que desde el punto de vista espiritual y psicológico desempeña en las protagonistas de ambas novelas. La integración de la música es parte de la configuración del discurso narrativo, y un modo de representar la búsqueda de la identidad, las interrogantes políticas y la comprensión de una existencia, al mismo tiempo esperanzada y amenazada por las circunstancias históricas y sociopolíticas.
\end{abstract}

\begin{abstract}
An analysis is provided of semantic relations, including symbolic elements, between certain forms of Afro-American music and Afro-Caribbean music (blues and reggae) and two novels by the Costa Rican author Anacristina Rossi. The role music plays in the main characters of both novels is discussed from spiritual and psychological perspectives. The integration of music is part of the formation of the narrative discourse and it is a way of representing the search for identity, political questions and the comprehension of an existence which is both fostered and threatened by historical and sociopolitical circumstances.
\end{abstract}

Palabras clave: novela costarricense contemporánea, música afroamericana, música afrocaribeñas, negritud en Costa Rica

Keywords: contemporary Costa Rican novel, Afro-American music, AfroCaribbean music, negritude in Costa Rica

1 Ponencia presentada en el XX Congreso Internacional de Literatura Centroamericana ( ciLca) 2012. Recibido: 30 de marzo de 2011; aceptado: 21 de abril de 2011.

2 Correo electrónico: lcraft@ northpark.edu

$$
\text { Letras } 49 \text { (2011), ISSN 1409-424X } 95
$$


La música sirve de metáfora organizadora de la historia narrada por la costarricense Anacristina Rossi en sus novelas ${ }^{3}$ Limón Blues (2002) y Limón Reggae (2007). Tanto el blues como el reggae son expresiones de la experiencia afroamericana/ afrocaribeña. El blues se asocia típicamente con un lamento que surge de la opresión; el reggae con esperanzas y añoranzas más utópicas. En este ambiente musical, los dos textos de Rossi presentan la historia de Costa Rica en el siglo xx desde la perspectiva de la mujer - una mulata cubanojamaiquina, una «paña woma» y una mulata árabe-libanesa - y de un moreno jamaiquino trasladado a la costa limonense. La historia de esta región es la de un aislamiento oficial de San José y del resto de la cultura costarricense de la sierra y el Pacífico; es también una historia de racismo, explotación laboral, sexismo, violencia, violación, paludismo, hambre y pobreza. Mientras se exploran en las novelas varias estrategias de resistencia de estas comunidades atlánticas, el texto ofrece la música como una fuerza que le brinda refugio y un espacio de donde pueden afirmar su dignidad e identidad.

La mayoría de los ensayos críticos sobre ambas novelas se han centrado en la cuestión de la identidad nacional y la construcción del sujeto subalterno en un espacio nacional conflictivo ${ }^{4}$. (Véase Molina Jiménez, Bachmann, Kearns, Rodríguez Chavarría, entre otros). Esta perspectiva sirve de punto de partida, pero lo que interesa es si Rossi puede ir más allá del espacio del subalterno (un lugar de

3 Anacristina Rossi, Limón Blues (San José: Alfaguara, 2002); Limón Reggae (San José: Ed. Legado, 2007). En adelante se indicarán entre paréntesis los números de página de cada novela (LB y LR), respectivamente.

4 Véase, entre otros, Pauline Bachmann, «La negociación de identidades culturales/nacionales: Representaciones del Caribe en las novelas Limón Blues y Columpio al aire», Istmo 17, 2 (2008); Sofía Kearns, «Anacristina Rossi's Limón Reggae: Pancaribbean Identity and Central American Politics», <www.lehman.cuny.edu/ciberletras/v18/kearns.html> (fecha de acceso 6 de enero de 2010); Iván Molina Jiménez, «Limón blues: una novela de Anacristina Rossi». Istmo <www.collaborations.denison.edu/istmo/n17/proyectos/bachmann.html> (fecha de acceso 6 de enero de 2010); y Stéphanie Rodríguez Chavarría, «Limón Blues de Anacristina Rossi: La negación del sujeto subalterno». Revista Pensamiento Actual, Universidad de Costa Rica VII, 8-9 (2007): 78-83. 
silencio si recordamos a Spivak ${ }^{5}$ ) y cómo integra varias formas de música afro-caribeña en su discurso para que se inscriba la costa limonense dentro del proyecto de la nación y la región.

Antonio Benítez-Rojo ha observado que en la música no hay significado (signified), solo significantes (signifiers) en combinaciones sin límites. La música es «la falta de significación» fuera del control del «Padre»-un Padre blanco y occidental, en contraste al texto literario que nunca puede escapar del orden simbólico patriar$\mathrm{cal}^{6}$. En este caso, la música en las novelas Rossi es un discurso auténtico de la negritud, de la comunidad afrocaribeña: el blues ${ }^{7}$ en la tradición de mucho arte y literatura de «black America», refleja un anhelo por la libertad y cierto «yearning for a home, for a proper place ${ }^{8}$; «te regresa a algo deseado» [traducción mía]) o algo perdi$\mathrm{do}^{9}$. En contraste, el reggae, un género que emerge más tarde en el Caribe, señala posibilidades utópicas para el futuro. Estos ritmos le permiten a Rossi estrategias para traducir y entender la experiencia de los afro-caribeños en Costa Rica.

El protagonista de Limón Blues, Orlandus, descubre su pasión por el blues y el jazz cuando está de visita en Harlem en 1918, como ayudante a Marcus Garvey y su UNIA, la «Universal Negro Improvement Association».

La música que oye en un bar [s]e parecía un poco a lo que Nanah [su madre jamaiquina] cantaba. Eran melodías y sin embargo no lo eran, se adelgazaban en el aire como columnas de humo. Su ritmo era

5 Cary Nelson y Lawrence Grossberg (Eds.), «Can the Subaltern Speak?», Marxism and the Interpretation of Culture. (Urbana, IL: University of Illinois Press, 1988) 271-313.

6 Antonio Benítez-Rojo, The Repeating Island. The Caribbean and the Postmodern Perspective, 2.a ed., James E. Maraniss (trad.) (Durham, NC: Duke UP, 1996) 271.

7 Cuando se usa el término blues, Rossi incluye una familia de formas musicales que se desarrollaron en la misma vena: blues, spirituals, gospel, jazz, rhythm and blues, aun ragtime, etc.

8 Elizabeth Schultz, «The Blues in Black Literature», Kansas English Journal 56.3 (1971): 19-23; ver, en particular, LeRoi Jones, citado por Schultz, 19.

9 Simeon Moss, «Writer Albert Murray Talks About the Blues, Jazz and Great Literature.» Cornell Chronicle Online (17 Oct 1996) www.news.cornell.edu/chronicle/96/10.17.96/albert_murray.html (Fecha de acceso: 26 de Julio de 2010). 
distinto, cuando uno esperaba un compás, no venía, sino que llegaba después, y a una velocidad diferente del resto. Pero no era una música apresurada, al contrario, lo hacía pensar en los hombres de Limón sentados en la acera jugando dominó, colocando las piezas de marfil en la mesa con un golpe fuerte y seco, conversando muy despacio y riendo mientras atrás tronaban las olas. (LB, 181)

Es una música de origen en un pasado lejano. Son ritmos que «vienen de Africa», que «llevamos adentro», le explica su madre (LB, 134). Martin Scorsese lo describe como «the most physical music I know, with an emotional undertow that's unlike absolutely anything else.... [Y]ou're hearing something from way, way back, something eternal, elemental, something that defies rational thought, just like the greatest art» ${ }^{10}$. Las ambivalencias que observa Orlandus son ejemplo de cómo, en estas formas musicales, se subvierte la noción de la secuencia al corazón de la lógica y sintaxis occidental ${ }^{11}$. Por estos «inscriptable values», según Piedra, formas como el blues y el son, entre otras, han sido vinculadas a comportamientos patológicos en el pensamiento occidental. La expresión de disposesión en el blues hace hincapié en «the incurable irregularities of logic and moody longings suggested by its name ${ }^{12}$.

«You play the blues to get rid of the blues», dice el crítico Albert Murray (citado en Moss). La vida de Orlandus Robinson Reed es una historia triste. «[D]emasiado apuesto para su propio bien: alto, ágil, musculoso, con unos ojos ardientes y una boca exquisita» (LB, 22), Orlandus se enamora perdidamente de una aristócrata blanca, Leonor, una «pañawoman»; y ella le responde. Este amor es la pasión de su vida. Como dice la letra de muchas canciones del blues, Orlandus experimenta «dolor mortal» $(\mathrm{LB}, 48)$; se siente

10 Martin Scorsese, «Preface». Martin Scorsese Presents the Blues: A Musical Journey (Nueva York: Amistad, 2003) 7.

11 José Piedra, «Through Blues», Do the Americas Have a Common Literature? (Durham, NC: Duke UP, 1990) 107-129 (121).

12 Piedra, 112-113. 
«herido y vacío (LB, 48), deprimido, acongojado (LB, 297), enfermo, solo, hechizado, un «zombie» (LB, 70), «absorto...e impenetrable (LB, 106). «Just thought I was dyin'» (LB, 54). También se enamora de una maestra bella e independiente, la mulata Irene, con quien se casa. Pero, aunque gozan de intimidad sexual, Orlandus nunca «podía hablarle, revelarle su ánimo» a Irene (LB, 127). Por su parte, Irene, enamorada de Orlandus pero algo decepcionada por su ensimismamiento, encuentra el amor de su vida en Ariel, médico judío de Estados Unidos. Tanto Orlandus como Irene tiene hijos de su amantes. El erotismo de estas relaciones - sus ritmos sensualeslo capta la imaginación de la autora, algo que vamos a examinar en más detalle al llegar a Limón Reggae. La trama de Limón Blues sigue un tema tradicional del blues, lo que Eileen Southern caracteriza como los «hard luck tales», especialmente de los amores difíciles ${ }^{13}$. «Bluesmen» escribe Alex Gibney, «are more than musicians; they are storytellers» ${ }^{14}$.

Por su dolor y profunda depresión, Orlandus se reconoce como hombre «bemolado»: un pianista le explica que el blues se distingue por sus «notas azules, que eran notas tristes» mientras las notas subidas son más optimistas. «El optimismo se llamaba 'sostenido' y lo contrario 'bemol'. Le dije que el bemol era triste pero más profundo. Asintió con la cabeza. Entonces me di cuenta. yo era un hombre en bemol. [Marcus] Garvey y el movimiento estaban en sostenido. Por eso a Garvey no le gustaba el jazz-blues» (LB, 281). En su estudio del blues, Southern sostiene que su melodía viene de una gama alterada en que el tercer, quinto, séptimo, y a veces el sexto, grados bajan a notas bemoladas. En estos puntos de la gama, el cantante emite un «'scoop', 'swoop', or 'slur'»: «[f]reely using such vocal devices as falsetto, shouting, whining, moaning, speaking, or growling,

13 Eileen Southern, The Music of Black Americans: A History, 2. ${ }^{a}$ ed. (Nueva York: W.W. Norton \& Co., 1983) 332.

14 Alex Gibney, «Foreword», Martin Scorsese Presents the Blues: A Musical Journey (Nueva York: Amistad, 2003) 8. 
the blues singer gives vent to his pain ${ }^{15}$. La improvisación es clave a la expresión de su emoción. Cuando al final de la novela Orlandus se muere de enfermedad y melancolía, se tocan blues y gospel en su entierro. Los gemidos del caracol de cambute «anunci[an] a los dolientes que el muerto había regresado a África» (LB, 371).

Los «hard luck tales» del blues operan no solamente en este nivel personal sino también en un mundo político y económico más amplio. Dice Steven C. Tracy, que «the blues...is an assertion of autonomy and a consolidation of power in the context of a world that wishes to diminish or eliminate that power» ${ }^{16}$. Orlandus y otros antillanos llegan a Costa Rica al principio del siglo xx en busca de trabajo y lo encuentran frecuentemente con la United Fruit, el «monopolio frutero» de Minor C. Keith. Éste tiene fama de ser «The Uncrowned King of Costa Rica», ya que el gobierno del país «le había regalado cientos de miles de hectáreas de las tierras más fértiles y...hasta hace poco no le había exigido ningún impuesto» $(\mathrm{LB}, 37)$. Otros lo conocen como «un janga manga...un gran crápula» (LB, 15). Orlandus tiene que trabajar para Keith después de descubrir que la finca que sus familiares habían cultivado en Cahuita - y adonde él quiere irahora pertenece al norteamericano. Le explican los policías quienes lo sacan de Cahuita que «en Costa Rica las fincas de los negros eran baldíos porque la República no quería propietarios africanos» (LB, 24). El racismo, el monopolio económico y la explotación laboralel gobierno y United Fruit reprimen una protesta tras otra-imponen condiciones intolerables a la población morena de la costa.

Emblemático del control imperial de la United Fruit en la región, el ferrocarril se extiende por toda la zona y depende de la mano de obra de los limonenses humildes. Desde su construcción a finales

15 Southern sigue: «Because of the performance practices associated with the singing of blues, it is almost impossible to accurately notate a blues melody on a staff. The notated melody can only approximate the melodic outline of the actual blues» (p. 334), más evidencia de su estatus ambiguo y ambivalente.

16 Steven C. Tracy, «The Blues Novel», The Cambridge Companion to the African American Novel, Maryemma Graham (Ed.) (Cambridge, UK: Cambridge University Press, 2004) 122-138(123). 
del siglo xix - cuando los padres de Orlandus migraron de Jamaica para contratar empleo con Costa Rica Railways - hasta el auge de su operación en los bananales durante los primeros treinta años del siglo XX, el tren representa esa época en movimiento y el motor de un «progreso» implacable. Es el capitalismo sin frenos. El tropo del tren aparece como una corriente subyacente en casi todos los capítulos de la novela desde el primero hasta la $\mathrm{Coda}^{17}$. Su importancia para el blues es indiscutible, nota el crítico Houston Baker ${ }^{18}$.

[T] he dominant blues syntagm in America is an instrumental imitation of train-wheels-over-track-junctures. This sound is the 'sign,' as it were, of the blues, and it combines an intriguing melange of phonics: rattling gondolas, clattering flatbeds, quilling whistles, clanging bells, rumbling box-cars, and other railroad sounds. The blues stanzas may then roll through an extended meditative repertoire with a steady train-wheels-over-track-junctures guitar backbeat as a traditional, syntagmatic complement. If desire and absence are driving conditions of blues performances, the amelioration of such conditions is implied by the onomatopoeic training of blues voice and instrument.

Murray también habla de la «locomotive onomatopoiea» en el blues (citado en Moss) ${ }^{19}$. En el tren de regreso después de despedirse de su amante, Orlandus — «herido fatalmente por la separación»empieza a canturrear cantos de su madre: «Am-ba you! Oh, am-ba you! E-do-o-o-o-o-». Cabeza, garganta y boca vibran con el movimiento del tren mientras se alivia «la pesadez de su corazón». Rossi salpica el texto con versos del blues, gospel, y canciones africanas

17 La Coda—el furgón de cola o «cabús» si seguimos con la imagen del tren—es la bibliografía anotada que agrega Rossi al final de la novela para explicar las fuentes históricas en su investigación para Limón Blues. Obviamente, el término italiano completa también el tropo de la composición musical.

18 Houston A. Baker, Jr., «Belief, Theory, and Blues: Notes for a Post-Structuralist Criticism of AfroAmerican Literature», African-American Literary Theory: A Reader, Winston Napier (Ed.) (Nueva York: New York University Press, 2000) 224-241 (233).

19 Moss (Murray), 58. 
relacionadas a las mismas formas mientras Orlandus y los limonenses se enfrentan con sus «deseos»y «ausencias».

El lenguaje del texto se aproxima onomatopéyicamente al canto y al ritmo del blues en varios pasajes. El ejemplo más destacado se ve/ se oye cuando miles de costeños se juntan en Limón, reunidos por Garvey y su organización afrocéntrica UNIA, para demandar liberación de la opresión de la «blancocracia» (LB, 254). Empiezan a entonar el ragtime, comparando su experiencia del cautiverio a la de Israel en Babilonia, y como anuncia el texto, «como lo iba a popularizar Louis Armstrong un poquito después, en los años treinta» (LB, 256). La muchedumbre hace cola como un tren largo, o «una inmensa culebra de colores ondulando, girando, meciéndose». Lo que sigue textualmente vale la pena ser citado por su ritmo «call and response», su sonido y corriente:

Port Limón bailaba, ondulaba y se mecía porque los hijos de Israel no se inclinan ante Nabucodonosor ni ante el ídolo de otro Sha drack ni ante nadie. Todos seguían a los músicos. Las bandas y las orquestas sacaron a Israel de Babilonia y dieron vuelta por el parque Vargas Sha drack y a ritmo de ragtime las Doce Tribus Olvidadas pero elegantes movían sus altos cuerpos fuertes Sha Drack en dirección a la plaza que habían alquilado. Mandó un ángel con alas de nieve que les habló del poder del Evangelio Sha drack. Y ardieron los soldados de Nabucodonosor, que eran centenares. Y los ángeles probaron una vez más que se recompensaba la paciencia, Sha drack. Y pudieron salir de Babilonia Sha drack. Y el líder va a sacarnos por fin de Babilonia, Sha drack. Y todos movían sus caderas como sólo saben hacerlo en el oeste de Africa, con ritmo preciso, con incomparable sensualidad. (LB, 256-257)

Hipnotizados por la belleza del gran sueño de la liberación, seducidos por las posibilidades de la repatriación a África, muchos siguen a Marcus Garvey en su proyecto de regresar «a sus raíces» e invierten sus recursos en empresas para lograr estos fines. Para 
Orlandus, este sueño resulta ser una gran decepción. Aunque el movimiento de UNIA y Garvey lo inspira a ayudarle al principio en sus preparaciones, Orlandus e Irene se dan cuenta de que pronto se fracasará por la subversión de afuera, corrupción de adentro, conducta inepta de los dirigentes y falta de visión: «Garvey hablaba mucho de la repatriación a Liberia y la liberación del África, y poco de cómo conseguir aquí y ahora una vida mejor» (LB, 263). Y se va a perder más que los sueños de regresar: las primeras décadas del siglo xx en la costa limonense ven el apogeo de una cultura negra intelectual y artística que en parte es patronizada por UNIA. Muchos de los antillanos que habitan Limón se consideran súbditos del imperio británico y, por eso, más «civilizados» que los otros costarricenses descendientes de los españoles (LB, 328). Instituciones como los periódicos distinguidos y respetados ${ }^{20} \operatorname{logias}$ y sociedades fraternales para hombres y mujeres, clubes literarios y templos, grandes orquestas y bandas florecen en aquel momento y cantan sus valores de «unidad, concordia, benevolencia», «[t]emperancia y control», «[h] umor, instrucción, perseverancia» (LB, 394).

Orlandus se enferma, sabiendo que todo está por perderse. Se encuentra cada vez más atrapado dentro de la organización hasta que una noche, en una recepción de UNIA en Harlem, sufre una crisis, mareado y ahogado: siente que «la recepción lo escupió por la puerta como un balín... [S]us pulmones estaban a punto de estallar y al abrir la boca le salió un grito fuerte pero sin aire» (LB, 284-5). Lo único que puede pronunciar es un ladrido: «syncopation!» (LB, 285). Busca un club de jazz y blues cuya «crisis armónica» $(\mathrm{LB}, 281)$ la va a entender en su propia crisis espiritual. Orlandus nunca sale de su depresión.

Samuel C. Nation, hombre honorable, asume el liderazgo del movimiento a favor de los derechos de los negros en Costa Rica, después de la muerte de Orlandus y la caída de Garvey (mediados

20 Sin embargo, la presión de United Fruit cierra uno tras otro. 
de la década de los treintas). Pero ya Nation es viejo. Irene, quien se encuentra sola al final de la novela ya que su amante Ariel también se muere, se pregunta «¿Cómo será Limón Town?» cuando desaparezca la generación de Nation (LB, 394). Todavía una mujer fuerte e independiente, ella lamenta que un mundo se vaya y que no se garantice otro seguro. Acompañada por Nation en su último baile en Limón (ella y sus hijos se trasladan a San José), Irene cierra la novela con sus pensamientos:

Y ya no sé si es buena idea haber venido a este baile, un erizo de mar me subió a la garganta, este brazo firme que me rodea la cintura es el brazo de Orlandus o el brazo de Ariel o es el brazo de este hombre que ya no estará más, nunca más, a mi lado y seré muy valiente excepto cuando escuche una risa parecida, un nombre parecido o la lluvia suavecita se escurra de las hojas y me recuerde su abrazo, sí, su abrazo, el de quién. (LB, 395-396)

Sus «notas azules» traducen la nostalgia por el amor perdido y un pasado irrecuperable. Irene, quien también ha padecido explotación y racismo, sin duda teme un futuro desconocido. Pero a diferencia de Orlandus, ella sobrevive. El blues le brinda refugio a él, memoria de lo deseado a ella. Limón Blues sirve de esta manera como una mirada hacia atrás sobre los eventos de la primera mitad del siglo xx en Costa Rica.

La novela más reciente de Rossi y la segunda del díptico, $\mathrm{Li}$ món Reggae, recuerda las transformaciones del país hacia finales del siglo xx. Rossi se sirve del reggae, música negra «desesperada y rebelde» que «encarna...el futuro, la juventud, la transmigración cultural de la diáspora africana» (LR, 175), como metáfora para (re) crear un mundo en transformación, que se extiende de la ciudad de Limón hasta un El Salvador en plena guerra de los ochentas, más allá a Belice y finalmente Nueva York. El reggae y los rastafari asociados en los años setentas tocaban ritmos y cantaban esperanzas utópicas 
no solamente para los afrocaribeños sino también para todos los marginados y sinvoces.

En esta novela - de una perspectiva más feminista que la previa— la joven protagonista Laura/Aisha, una «tica árabe» (LR, 173), queda hipnotizada la primera vez que oye el ritmo sensual e irresistible que «la noqueó» $(\mathrm{LR}, 107)$. Sin embargo, lo que le promete liberación - como mujer, como caribeño-centroamericana, como ser humana - se queda trunco por la degradación que sigue la promesa de las guerras de liberación nacional en la violencia posguerra del istmo. Pero Laura/Aisha se niega a rendirse por completo a la nueva «inopia». La música le brinda refugio, un sitio de resistencia en la lucha $-\mathrm{o}$, para seguir con nuestra metáfora - la danza entre los sueños utópicos de la modernidad y la realidad caótica posmoderna.

Antes de abordar la función del reggae en el texto, será necesario examinar el contexto social y político en que emerge en Centroamérica y el Caribe como forma de arte. Le toca a Laura/Aisha vivir en una Costa Rica «unificada» a finales del siglo xx; es decir, unificada en cuanto al sentido de incluir oficialmente en el espacio nacional tanto la costa limonense como la meseta central y el Pacífico. ${ }^{21}$ De ascendencia libanesa por su madre y mulata por su padre, Laura resalta uno de los valores principales de la cultura árabe que «es su hospitalidad» (LR, 36). Así, es una joven abierta a las riquezas de la diversidad. Prefiere la cultura de Limón con su tradición que viene del principio del siglo xx, como lo vimos en Limón Blues, un lugar «apasionante y completamente desconocido para cualquier ticomeseteño. Un Limón cosmopolita, multilingüe y multicultural, sensual, colorida pero no de tarjeta postal, sino de gran ciudad, de

21 Hasta mediados del siglo xx, los limonenses y otros afrocaribeñas — anteriormente de Jamaicaeran súbditos británicos y aislados del resto de Costa Rica hasta que el Presidente Figueres les dio nacionalidad. Sin embargo, su ciudadanía no cambió su mal tratamiento por los paña (blancos). Según Bachmann, el Caribe hasta ahora sigue como «espacio negado» en los proyectos nacionales (5), lo que es irónico ya que esta afro-comunidad de Limón fue el grupo más culto del país al principio del siglo xx tanto para hombres como para mujeres (Rossi, Istmo 2). Es el tema de la novela anterior de Rossi, Limón Blues (2002). 
puerto abierto al mundo», escribe María Lourdes Cortés (en Delga$\mathrm{do}^{22}$ ). En vez de quedarse mucho tiempo con sus padres en San José, Laura frecuenta la casa de una tía soltera, La Maroz, quien la llama por sus nombres árabes, Aisha y Habibi. La joven nos explica que se siente incómoda en su propio país y que no pertenece a la sociedad capitalina dominante, ya que ésta niega o excluye la presencia indígena y afrocaribeña del territorio nacional, optando por lo blanco y lo homogéneo ${ }^{23}$. En una referencia intertextual, Aisha expresa su admiración por el héroe de la película, Lawrence de Arabia, obstinado y valiente en su solidaridad con los árabes rebeldes contra el imperio; pero lamenta su fracaso porque «los árabes fueron incapaces de unirse en un momento crucial» (LR, 42-43). Las simpatías de Laura/ Aisha están con el subalterno, los marginados y los vencidos.

Recibe su educación política en Limón, juntándose con elementos de la UNIA y los Panteros Negros (inspirados por los movimientos de liberación de aquel momento en Estados Unidos). Sospechada por no ser suficientemente negra - la llaman «paña girl» (blanca) - , Laura/Aisha, no obstante, negocia las varias etnias y razas, trabajando diligentemente por la justicia para los afrocaribeños. A Laura/Aisha le atrae el espíritu inclusivo del Black Panther Party que es «el único partido revolucionario mundial que incorpora la liberación femenina y la liberación gay» (LR, 31). Sus ideales políticos la llevan a Laura/Aisha eventualmente a luchar con los campesinos y obreros en las guerras de liberación nacional de El Salvador en la década de los ochentas.

$\mathrm{Al}$ involucrarse en la guerrilla salvadoreña, Laura habla con una compañera sobre sus motivos; ésta le explica que luchan «para eliminar lo peor y forjar el hombre nuevo», a lo cual Laura pregunta, « ¿Y la mujer nueva?», insistiendo en que el verdadero revolucionario «cambi[e] su lenguaje» (LR, 125-126). Laura/Aisha representa esta nueva mujer - militante, independiente y al mismo tiempo erótica. 22 Manuel Delgado, «Limón Blues de Ana Cristina Rossi». Reseña para Club de Libros, 4.

23 Bachmann, 4. 
En este sentido Rossi sigue la línea de muchas escritoras centroamericanas en los últimos treinta años tras el ejemplo de la guatemalteca Ana María Rodas ${ }^{24}$. Laura se inspira en su tía Maroz, mujer/mentora que rechazó el matrimonio porque no quería «perder mi felicidad» y rendirle a otro ser humano el control de su propio cuerpo y mente. Dueña de una empresa, Maroz sabía tratar con justicia a sus empleados, escuchando sus preferencias por el horario de trabajo y los fines de semana libres antes de que otros respetaran los mismos derechos de los trabajadores. Además de darle a la joven Laura el orgullo de sus raíces árabes, le da la libertad de «andar libre» por las calles de Limón explorándolo (LR, 18).

Laura reúne dos ideales feministas de la época de las guerras de liberación nacional: el de la mujer militante y el de la madre, simultáneamente, como si estuviera dando a luz a la nueva nación. Mientras lucha en las montañas con la guerrilla salvadoreña, busca refugio en las trincheras abrazando a un huérfano, Toño; lo acompaña al «hospital popular» después de que éste sufre una lesión a la cabeza; lo rescata de una matanza de niños. El «cipote» empieza a «llamarla mamá» (LR, 142). Las circunstancias los separan, sin embargo, y lo que promete dar posibilidades de acabar en la adopción no se realiza.

Mujer independiente, Laura/Aisha logra escapar del infierno bélico de El Salvador sin haber abandonado su fe en la revolución. En Costa Rica sigue preparándose para convertirse en pintora. Con sus sensibilidades artísticas, Laura/Aisha se intoxica de los colores, olores y sonidos del Caribe costarricense, lo que se aprecia desde la primera página de la novela en el ritmo de la prosa de Rossi:

Cada vez hay más pobres aquí en el mercado, piensa, y en ese instante una ola verde se levanta y crece y crece y se revienta contra los farallones de Manzanillo y es como si estallara contra su pecho, queda bañada en espuma blanca, esa capacidad que tiene Laurapara 24 Véase Poemas de la izquierda erótica (1973). 
hundirse en una imagen que al principio es un color, por ejemplo verde, un color que crece hasta volverse ola que estalla y se abre y despliega otros colores: el cielo celeste, el verde oscuro de los bosques del acantilado, el mismo acantilado color natilla. (LR, 9)

La ponen «eufórica» los olores del mercado, de los negros en el tren, del aire muy dulce y suave, perfumado (LR, 13). Cortés se refiere a la «exuberancia» y la «audacia» de la narrativa de Rossi ante lo erótico, que «se trasladaba del cuerpo de los personajes a la Naturaleza» ${ }^{25}$. La crítica lo explica como el cumplimiento de «la historia de amor de La loca de Gandoca [primera novela de Rossi]...una catarsis que hace Anacristina para explicarnos las raíces de su pasión por el Caribe, pasión que la hizo pelear por Gandoca» ${ }^{26}$. La sensualidad de Laura/Aisha, esta «nueva mujer» arraigada en un ambiente fecundo y amenazado, la lleva a los brazos de unos cuantos amantes que comparten su pasión, su política o su idealismo.

Los «cuerpos esbeltos y los peinados afro» que bailan al nuevo ritmo en los bares del Limón nocturno seducen a Laura. Ésta trata de situarla en las corrientes de la música caribeña: «No era rock ni jazz ni calipso ni góspel ni blues pero era indudablemente una música negra, una música afro....» (LR, 107). La describe en términos rítmicos, casi sexuales: «La vio como una ola levantarse despacito y crecer y crecer y cuando se dio cuenta ya estaba empapada, tomada por la ola. Era como el suave gemido del mar pero debajo latía un ritmo vigoroso cuyo poder estaba en el silencio entre compases» (LR, 107). Repite Laura, como un tambor insistente, que lo mágico de esta música es el silencio en que están «el poder y la gloria». Cuando ella está en plena guerra en El Salvador, para evitar el sufrimiento vuelve a pensar en «el compás

25 Delgado, 2.

26 Delgado, 4. Hay fuertes ejemplos del discurso medioambientalista en Limón Reggae también. Rossi pone en duda los proyectos estatales como el de Cahuita Monumento: el estado declaró los bosques y cacaotales de los finqueros afrocaribeños bajo protección nacional, privándoles de sus fuentes de ingresos: «A todos se nos cayó el mundo. Éramos gente tranquila y próspera sembrando cacao y venían a quitarnos la prosperidad» (LR, 233). 
contenido el compás que se arrasaba y tardaba en llegar y en esa espera estaba la gloria» (LR, 121). Por el reggae, ha «tocado el cielo y el centro de la tierra» (LR, 176); está en una «unión» con la tierra (LR, 198); está conectada «con una esencia loca, melancólica, animal...» (LR, 108).

Lo que siente Laura/Aisha al oír el reggae y la voz del «carismático» Bob Marley (LR, 175) parece una unión mística, casi religiosa. Ésta la compara a veces con música de los «revival» (LR, 175). El ritmo, según Léopold Senghor,

is the architecture of being, the inner dynamic that gives it form, the pure expression of the life force. Rhythm is the vibratory shock, the force which, through our senses, grips us at the root of our being. It is expressed through corporeal and sensual means....[R]hythm turns all these concrete things toward the light of the spirit. In the degree to which rhythm is sensuously embodied, it illuminates the spirit.... Only rhythm gives the word its effective fullness; it is the word of God, that is, the rhythmic word, that created the world ${ }^{27}$.

Comentando las observaciones de Senghor, Antonio BenítezRojo dice que el ritmo es lo que distingue al Caribe, un «espacio polirítmico» donde se reúnen corrientes africanas, cubanas, europeas, asiáticas e indoamericanas ${ }^{28}$. Su carácter híbrido señala posibilidades utópicas: «Within this chaos of differences and repetitions, of combinations and permutations, there are regular dynamics that coexist, and which, once broached within an aesthetic experience, lead the performer to re-create a world without violence» ${ }^{29}$. La música tiene su propia expresión que no se somete a las reglas del lenguaje ni su violencia. Sirviéndose de teorías del análisis psicoanalítico, Benítez-Rojo ve más (sobre todo en sus estudios de los textos de Alejo Carpentier) las estructuras circulares del «viaje musical», el deseo por la Madre en el triángulo adipal (y no el Padre), y la búsqueda del

27 Benítez Rojo, 80-81.

28 Benítez Rojo, 75, 81.

29 Benítez Rojo, 81. 
paraíso perdido en que el Yo y el Otro componen el mismo cuerpo (LR, 272). Lo que Laura/Aisha y sus compañeros oyen en el reggae los une el uno al otro, a sus ideales y al resto del mundo.

A mediados del siglo xx, observa Laura, la música de Limón «está muerta o escondida». El calypso, uno de los antecedentes del reggae en el Caribe costarricense, ya no sirve. Valeria Grinberg Pla explica que el calypso, «crónica cantada» con su «resistencia oblicua», todavía retiene un «carácter eminentemente masculino»; presenta imágenes negativas de las mujeres ${ }^{30}$. Laura busca algo más, que prometa liberación (LR, 176). La música que descubre es un nuevo sonido de Belice, de Jamaica: «[L]a música era cosa seria, de tambores y cantos garífunos al steel band trinitario pasando por cientos de gamas caribeñas para desembocar en el reggae» (LR, 176). Sus raíces son diversas, quizá emblemáticas de la visión inclusiva y utópica que se anuncia. ${ }^{31}$ «[L]a música reggae representa la utopía que se niega a morir,» escribe Doriam Díaz ${ }^{32}$. La misma autora Rossi nota que el baile constante de los negros les da un «refugio en una Costa Rica que no los quería $»^{33}$, tema repetido de Limón Blues. Afirmando esta realidad, Laura dice que «algunas personas viven tan azotadas que sólo se abren con la música» (LR, 106). Ellos han encontrado un nuevo ritmo de esperanza o, por lo menos, protección.

También a Laura/Aisha la atrae la visión rastafari asociada con la música reggae, el ideal de un solo mundo unido. Uno de sus amantes de Limón, Raymond, la seduce precisamente por su generosidad yespíritu

30 Valeria Grinberg Pla, «El calypso en el caribe costarricense: Crónica cantada de una comunidad transnacional», Istmo 17, <www.collaborations.denison.edu/istmo/n17/articulos/ grinberg.html>, (fecha de acceso 6 de enero de 2010), pp. 9, 5 y 10, respectivamente.

31 El crítico músico Piero Scaruffi, en su History of Popular Music, estudia el desarrollo del reggae cuyas raíces están en los rhythm \& blues de Nueva Orleans. La paradoja del reggae es «that this music 'unique to Jamaica' is actually not Jamaican at all, having its foundations in the USA and Africa», <www.scaruffi.com/history/reggae.html>.

32 Doriam Díaz, «Anacristina Rossi regresa a Limón en su nueva novela», Nación.com, Aldea Global (19 de julio de 2007), <http://wvw.nacion.com/ln_ee/2007/julio/19/aldea1172552.html>, (fecha de acceso: 6 de enero de 2010).

33 Anacristina Rossi, «Entre los vestigios», Istmo V, 1 (2003): 2, <www.collaborations.denison.edu/ istmo/n17/proyectos/bachmann.html>, (fecha de acceso: 6 de enero de 2010). 
abierto: «Raymond es el único afrodescendiente que no me rechazó, y fue porque era rastafari». Añade que «el rastafari y el reggae son ecuménicos» (LR, 281). Como los otros rastafari, Raymond cree que el emperador de Etiopía, Haile Selassie, negro y cristiano, es el descendiente directo de David y Salomón. Ése rechaza los valores de «Babilonia», el imperio británico y los otros racistas y clasistas, afirmando que «los negros sí somos humanos y lo que pasa es que los blancos blanquearon la historia» (LR, 207) ${ }^{34}$. Se adopta el pelo de los «dreads» para distinguirse de los demás y para «recordar que nunca, bajo ningún pretexto, podremos integrarnos a Babylon, a la sociedad» (LR, 207). A Laura/Aisha «varias cosas de rastafari le parecieron bien, su amor por la libertad, la actitud radical de salirse de Babylon o más bien de superarlo, de situarse por encima de todos los prejuicios» (LR, 209). Lo ideal sería «superarlo», pasar más allá del racismo, clasismo y sexismo. Pero en el texto se pregunta si en realidad se puede cambiar esta Babilonia. La música le abre aLaura/Aisha la posibilidad de algo mejor.

Lo que finalmente frustra sus sueños es la aparición de las maras, o pandillas, una nueva violencia más horrífica que la de las guerras de liberación nacional. La utopía soñada resulta derrocada y desaparecida. No hay alguna música asociada a las maras. Laura se da cuenta de que «el ideal por el que vivía se esfumaba, se enfermó» (LR, 271). Desde

34 Haile Selassie habló a la ONU en octubre 1963 sobre su visión de un mundo libre del racismo. Sus palabras proponen una visión utópica: «On the question of racial discrimination, the Addis Ababa Conference taught, to those who will learn, this further lesson: That until the philosophy which holds one race superior and another inferior is finally and permanently discredited and abandoned: That until there are no longer first-class and second class citizens of any nation; That until the color of a man's skin is of no more significance than the color of his eyes; That until the basic human rights are equally guaranteed to all without regard to race; That until that day, the dream of lasting peace and world citizenship and the rule of international morality will remain but a fleeting illusion, to be pursued but never attained; And until the ignoble and unhappy regimes that hold our brothers in Angola, in Mozambique and in South Africa in subhuman bondage have been toppled and destroyed; Until bigotry and prejudice and malicious and inhuman self-interest have been replaced by understanding and tolerance and good-will; Until all Africans stand and speak as free beings, equal in the eyes of all men, as they are in the eyes of Heaven; Until that day, the African continent will not know peace (Africa Source, E-journal $<$ http://www.africaresource.com/index.php?option=com_content $\&$ view=article \&catid=36:essa ys-a-discussions\&id=240:haile-selassies-1963-address-to-the-united-nations\&Itemid=346>) . 
las primeras páginas de la novela hasta el final, Laura/Aisha se fija en cierto «eso» que descubre en los barrios marginados, un «potente olor a podredumbre, a animal muerto» que se ve en las caras de los jóvenes con sus bocas deformadas, despiadadas, feroces; es una degradación o humillación, simbolizada por los «agónicos maullidos» que oye de los gatos que los niños torturan o por la caca que ponen en la entrada de su casa (LR, 14-15). Este «eso» o «algo» la obsesiona desde la infancia (LR, 273); «'Eso', 'algo', es intensamente humano, los animales no lo hacen; es degradar la vida, desmontarla hasta su núcleo y ver un trozo de carne neutra palpitando, sufriendo» (LR, 182). Al final de la historia, Laura sabe que el niño Toño que rescató y cuidó durante la guerra en El Salvador se ha hecho marero, viviendo de extorsiones y asesinatos (LR, 288). Según Laura, «el fondo de la degradación es la mara. No tengo palabras para contártelo. Es más salvaje que la guerra. Es el infierno. Es la guerra sin sentido, lo que ellos llaman la vida loca» (LR, 287). Pensando que puede salvar a Toño de la mara, lo lleva a Costa Rica. Pero él vuelve a juntarse allí con los mareros, y Laura se da cuenta de la futilidad de sus esfuerzos: «Toño no iba a salir de ese mundo, no quería salir» (LR, 289). Parece que las esperanzas de Laura por Toño se le van en un malparto simbólico; pierde a «su hijo». Sin embargo, en los últimos párrafos de la novela, vemos a Laura/Aisha y su amiga salir una vez más tras el niño mientras pone el reggae de Bob Marley: «Every little thing is gonna be all right» (LR, 291).

No se sabe si se encuentran con Toño o no. Laura está decidida a seguir buscándolo, a pesar de que sus instintos le dicen que Toño ha desaparecido para siempre en el inframundo de las maras. Toño es emblemático del fracaso de los sueños utópicos en la posguerra, lo que Rodríguez ve desarrollado en las «novelas de la destrucción nacional», llenas de «criminalidad», pandillas, narcotraficantes, terroristas y otros «desechables» (5). En los textos que surgen de esta nueva realidad, observa Werner Mackenbach, «no se proponen más mitos, no se cantan canciones heroicas ni se evoca a los mártires. Las grandes propuestas colectivas utópicas han cedido ante una mirada 
crítica sobre el morir y matar individual» (PL, 3). Es probable que a Toño lo maten en una pelea; con él mueren las esperanzas en una sociedad mejor. Rossi escribe el epitafio para la revolución cuando Laura/Aisha recibe las noticias del asesinato de los jesuitas de la Universidad y el exterminio de muchos de la población civil en barrios pobres: «El mundo no escuchó» (LR, 270). El gobierno vuelve a exterminar a los pobres y la guerrilla se retira.

En esta novela, el reggae es lo único que le satisface a la protagonista. La escucha en trance, transportada a otro mundo por vapores de «bairrún, marihuana y pachulí» (LR, 260). En la vida de cada día, Laura/Aisha no encuentra a su «príncipe azul» aunque tiene unos cuantos amantes, aunque conoce la verdadera pasión. Se parece mucho a su tía Maroz que nunca se casa y está bastante contenta con este estado. Además, en una inversión del mito de la búsqueda del padre, la «madre Laura/Aisha» busca a su «hijo» - juntos en la guerra, separados por la «paz»y las maras. Pero no lo encuentra. Ella se queda con algunos compañeros y la esperanza de una loca de encontrarse con un niño perdido.

La realidad en el mundo de las dos novelas es complicada; se compone más de sueños truncos y futuros inciertos que de hilos atados. Orlandus se rinde; Irene y Laura/Aisha sobreviven sin nada más que unas cuantas esperanzas y su dignidad. Por medio del blues, los personajes en Limón expresan su desilusión y regresan a tiempos mejores y espacios más acogedores. El reggae les anuncia un futuro de paz y amor universal. So testigos de diversos fracasos: la muerte de una civilización brillante en Limón, la muerte de ambiciones de ser repatriados a África, y la muerte de sueños con la revolución y la liberación nacional. Para mal citar a Marley, «Every little thing NOT gonna be all right» (énfasis mío). Lo que los salva es que convierten en música sus dolores, odios, y añoranzas en arte ${ }^{35}$. El compás sigue, el son de la utopía no. Por lo menos, la pieza está inacabada; pero el gran final no se garantiza.

35 Schultz, 22. 